\title{
Effect of Ergotamine on Headache and Migraine Attack Induced by Sindenafil Citrate
}

Rayka Sharifian ${ }^{1}$, Ayoub Barzgarnejad ${ }^{2 *}$, Fatemeh Ghanbarpour ${ }^{1}$, Mehrdad Taghipour $^{1}$

1.Student Research Committee, Faculty of Medicine, Mazandaran University of Medical Sciences, Sari, Iran 2.Department of Urology, Faculty of Medicine, Mazandaran University of Medical Sciences.

\begin{abstract}
Sildenafil citrate is a potent vasodilatation agent to treat male erectile dysfunction and pulmonary hypertension. Among its adverse effects, headache and migraine attack have been widely reported. Here we focus on the effect of sildenafil, a selective inhibitor of CGMP hydrolyzing phosphodiesterase-5 (PDE-5), on headache induction. PDEs are large families of enzyme that break down cyclic nucleotides CGMP. When PDEs are inhibited, the levels of CGMP increase within vascular smooth muscle cells resulting in relaxation and vasodilatation in peripheral and cerebral vessels. This mechanism leads to headache. Many methods have been tried to treat headache including a pharmacological and non- pharmacological managements. In this paper, we hypothesize that ergotamine can be used to reduce the headache and migraine attack induced by sildenafil. Undoubtedly, the most important and conspicuous pharmacological effect of ergotamine is its vasoconstrictor action. This mechanism of ergot is in contrast with vasodilator action of sildenafil that can remit headache and migraine attack.
\end{abstract}

Keywords: Sildenafil; headache; migraine; Ergotamine

\section{Introduction}

Human experimental migraine model has been useful in suggesting novel anti-migraine pharmacological target $(1,2)$ and in the analysis of signaling pathways involved in the induction of the headache and migraine response $(3,4)$. The nitric oxide (NO) hypothesis of migraine that is well-established (3) and studies in healthy volunteers and migraine patients with highly selective inhibitor of phosphodiesterase type 5 (PDE-5) sildenafil $(4,5)$ have demonstrated that cyclic guanosine monophosphate (cGMP) is a likely mediator of headache responses elicited by NO. Sildenafil citrate is an inhibitor CGMP specific PDE-5 in smooth muscles where PDE-5 is responsible for degradation of cGMP. Sildenafil citrate increase cGMP within vascular smooth muscle cells,

\section{Corresponding author:}

Ayoub Barzgarnejad

Department of Urology, Faculty of Medicine, Mazandaran University of Medical Sciences.

Email: ayubbarzgarnejad@gmail.com

Received: 16-06-2013 Accepted: 27-06-2013 Published: 10-07-2013

doi:10.7575/aiac.abcmed.v.2n.1p.30 
resulting in relaxation and vasodilatation. Headache has been noted as a side effect of sildenafil in clinical trials with a prevalence of about 11 to 16 percent. Recent experimental studies have shown that in young persons, especially females, the side effect occurs in most of subjects. It also has been proven that in migraine patients sildenafil usually induces a migraine attack. Migraine sufferers should be warned of this side effect (6).

\section{Hypotheses}

In this paper we hypothesize that ergotamine can be used to remit headache and migraine attacks induced by sildenafil. The treatment which we considered can reduce this complication of sildenafil. An overview of the concept is presented in Figure 1.

Fig. 1 Algorithm of ergotamine effect on headache and migraine attack induced by sildenafil provided in Figure 1.

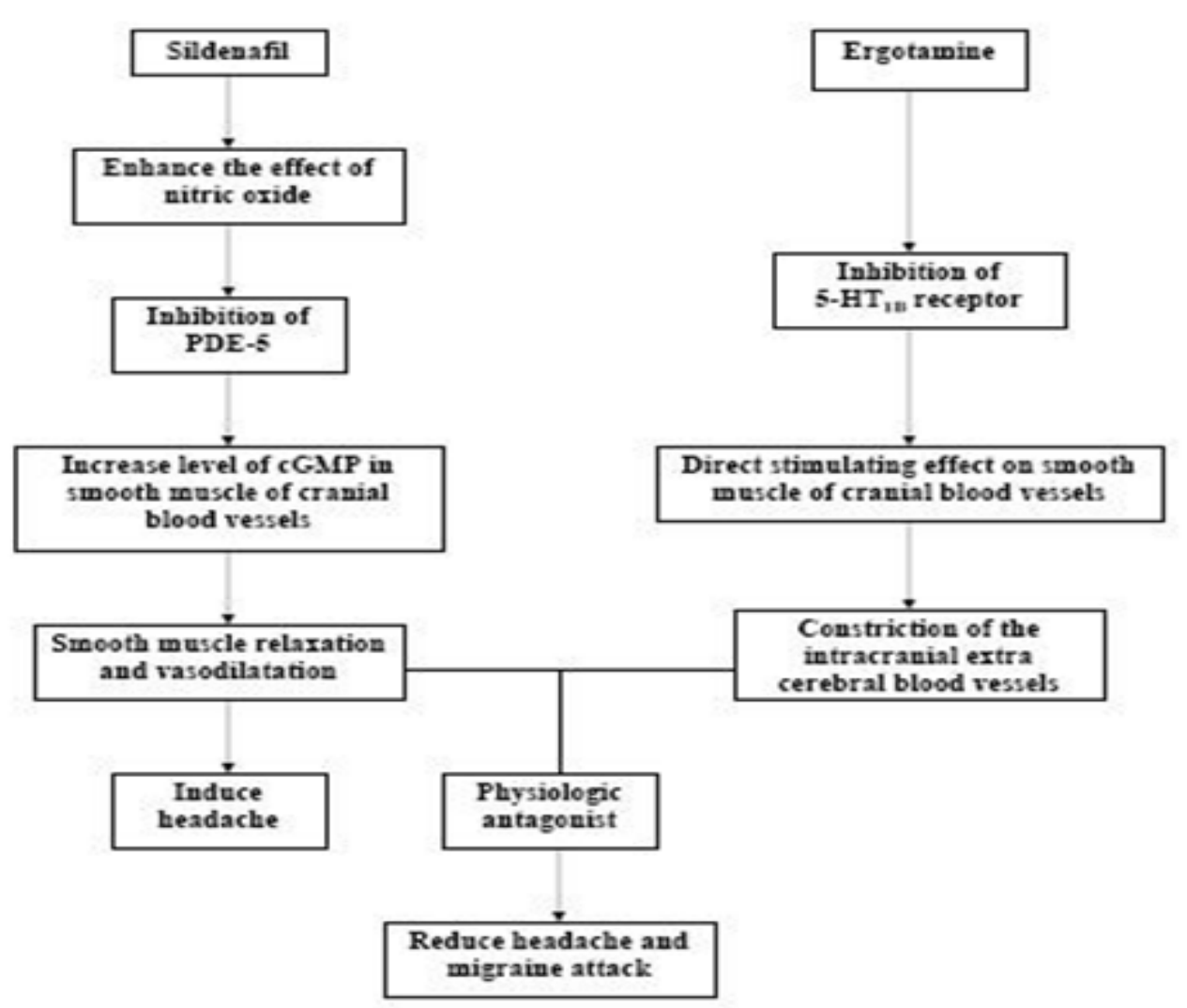

\section{Results and discussion}

Data from homodynamic studies show that increasing the doses of sildenafil is associated with increased plasma cGMP levels (7). The physiological actions of cGMP are limited to their area of synthesis by their hydrolysis to GMP by cyclic nucleotide phosphodiesterases (PDE) or by their export from the cell. From 11 reported PDE isozymes, PDE5 is considered to be the most active cGMP-hydrolyzing PDE in smooth muscle (8). PDE5 has a high affinity for cGMP [a second messenger whose bioactivity is triggered by NO] and is selectively inhibited by compounds such as sildenafil $(9,10)$. The mentioned mechanism leads to smooth muscle relaxation and cerebral vasodilatation. Headaches and other symptoms due to vasodilation were the most commonly reported adverse effects of sildenafil treatment. The consequences after applying single oral doses 
of sildenafil of $25-100 \mathrm{mg}$ were moderate (11, 12). There are several methods for treatment of headache and migraine attacks. In this paper, we propose Ergotamine as a treatment of headache and migraine attack induced by sildenafil. Ergotamine is one of several peptide alkaloids isolated from ergot. As described in the classic studies (13), ergot alkaloids were the first adrenergic blocking agents discovered. They have complex multiple effects on smooth muscle, blood vessels and neurons, acting as partial agonists or antagonists at alpha adrenergic, serotonergic (5-HT1 receptor) and dopaminergic receptors. Ergotamine has been used for many years as a vasoconstrictor to suppress vascular headaches, especially to abort acute migraine headache with or without aura (14)

\section{Consequence of hypotheses}

Successful treatment of headache induced by sildenafil is based on the vasoconstrictor mechanism of ergotamine in cerebral vessels. If this hypothesizes proves to be correct, we expect that ergotamine could relief the sildenafil-induced headache.

\section{Conflicts of interest}

The authors declare that they have no conflict of interest.

\section{References}

1. Lassen LH, Ashina M, Christiansen I, Ulrich V, Grover R, Donaldson J et al. Nitric oxide synthesis inhibition: a new principle in the treatment of migraine attack. Cephalalgia 1998; 18:27-32.

2. Lassen LH, Haderslev PA, Jacobsen VB, Iversen HK, Sperling B, Olesen J. CGRP may play a causative role in migraine. Cephalalgia 2002; 22:54-61

3.Thomsen LL, Olsen J. Nitric oxide in primary headaches. Curr Opin Neurol 2001; 14:315-21.

4. Kruuse C, Thomsen LL, Birk S, Olsen J. Migraine can be induced by sindenafil without changes in middle cerebral artery diameter. Brain 2003; 126:241-7.

5. Kruuse C, Thomsen LL, Jacobsen TB, Olesen J. The phosphodiesterase 5 inhibitor sildenafil has no effect on cerebral blood flow or blood velocity, but nevertheless induces headache in healthy subjects. J Cereb Blood Flow Metab 2002; 22:1124-31

6. Headache Classification Subcommitee of the International Headache Society. The International Classification of Headache Disorders, 2nd edition. Cephalalgia 2004; 24(suppl. 1): 9-160.

7. Graham Jackson, MD, Nigel Benjamin,MD,Nevile Jackson,MD, and Michael J.Allen, MD,Effects of Sildenafil Citrate on Human Hemodynamics.Am J Cardiol 1999;83 : 13C-20C

8. Raybalkin SD, Yan C, Bornfeldt KE, et al. cyclic GMP phosphodiesterases and regulation of smooth muscle function. Circ Res.2003; 93:230-291.

9. H.A. Ghofrani, I.H.Osterloh,F.Grimminger. Sildenafil: from angina to erectile dysfunction to pulmonary hypertension and beyond, Nat. Rev.Drug Discov. 5 (2005) 689-702

10. Anna Caretti a, Monica Fantacci a, Dario Caccia b, Michele Perrella . Kenneth C.Llowe c, Michele Samaja. Modulation of the NO/cGMP pathway reduces the vasoconstriction induced by a cellular and PEGylated haemoglobin, Biochimia et Biophysia Acta 1784 (2008) 1428-1434

11. Goldstein H, Lue TF, Padma-Nathan H, Rosen RC, Steers WD, Wicker PA. Oral sildenafil in the treatment of erectile dysfunction. N Engl J Med 1998;338:1397-1404

12. Morales A, Gingell C, Collins M, Wicker PA, Osterloh IH. Clinical safety of oral sildenafil citrate(VIAGRA) in the treatment of erectile dysfunction. Int J Impot Res 1998:10:69-74.

13. J. J. Ibraheem, L. Paalzow, P. Tfelt-Hansen. Kinetics of ergotamine after intravenous and intramuscular administration to migraine sufferers. Euro J Clinic Pharma 1982; 23:3: 235-240

14. Joanne Moore. Ergotamine. University of Oklahama, College of Med, Oklahama City, USA. Elsevier Inc. 2007 